\title{
Patients with Ovarian Clear Cell Carcinoma Are at High Risk of Secondary Malignancy
}

\author{
JMV Nguyen ${ }^{a}$, D Vicus ${ }^{b}$, MQ Bernardinic, LF Hogenc. \\ Division of Gynecologic Oncology, University of Toronto, Toronto, Canada \\ b Division of Gynecologic Oncology, Sunnybrook Health Sciences Centre, University of Toronto, Toronto, Canada \\ c Division of Gynecologic Oncology, Princess Margaret Cancer Centre, University of Toronto, Toronto, Canada
}

\section{BACKGROUND}

- Ovarian clear cell carcinoma (OCCC) accounts for $5-25 \%$ of all subtypes of epithelial ovarian carcinoma.

- OCCC has unique clinical and molecular features compared to other epithelial ovarian cancer histologies.

- Previous studies have identified an increased risk of secondary malignancy (SM) in patients with ovarian cancer, but none have focused solely on the clear cell histology.

\section{OBJECTIVES}

- The primary objective was to describe the incidence and types of secondary malignancies in patients diagnosed with pure OCCC.

- Secondary objectives were first, to identify risk factors associated with the development of SM and second, to evaluate the impact of SM on survival, including overall survival and progression-free survival (pending).

\section{METHODS}

- Retrospective cohort study of all patients diagnosed with pure OCCC who received primary treatment and were followed at Princess Margaret Cancer Centre and Sunnybrook Health Sciences Centre in Toronto, Ontario,

Canada, between 1992 and 2017.

- Institutional tumor registries were used to identify patients.

- All OCCC diagnoses were read by pathologists specialized in Gynecology and were confirmed through central pathology review.

- We excluded patients with histologies other than pure OCCC (such as mixed clear cell histology).

\section{RESULTS}

\section{9 patients with OCCC}

53 developed a SM (25.4\%), of whom 7 developed 2 SM.

SM types included: breast (13), skin (9), gastrointestinal tract (9), other gynecologic malignancies (8), thyroid (6), lymphoma (3), head and neck (4), urologic (4) and lung (4) malignancies.

18 occurred before the index OCCC, 35 after the indec OCCC, and 7 were diagnosed concurrently.

\section{Secondary Malignancies}

\begin{tabular}{lcl}
\multicolumn{1}{|c}{$\begin{array}{c}\text { Type of Secondary } \\
\text { Malignancy }\end{array}$} & $\begin{array}{c}\text { Number of } \\
\text { patients }\end{array}$ & \multicolumn{1}{c}{ Examples } \\
\hline $\begin{array}{l}\text { Breast } \\
\text { Skin }\end{array}$ & 13 & Melanoma (3) \\
Gastrointestinal & 9 & $\begin{array}{l}\text { Stomach, appendix, anal, esophagus, } \\
\text { rectosigmoid }\end{array}$ \\
Other gynecologic & 9 & Endometrium (2), vagina, vulva \\
Thyroid & 8 & Nasopharynx, tongue \\
Head and Neck & 6 & Kidney (2), bladder \\
Urologic & 4 & \\
Lung & 4 & \\
Lymphoma & 4 & \\
\hline
\end{tabular}

\section{Patient demographics}

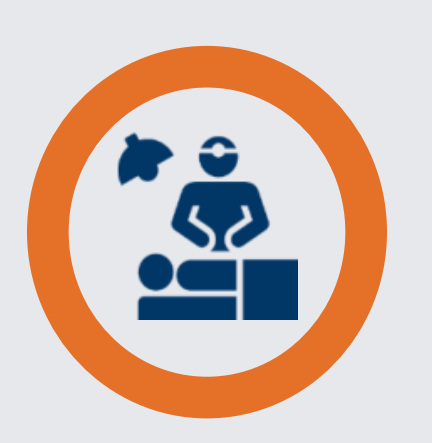

There were more smokers in the group of patients who developed a secondary malignancy. There were no other differences in other demographic characteristics.

\section{CONCLUSIONS}

-Our study is the first to describe an elevated risk of SM in this patient population, and to evaluate the effect of SM on survival.

- Our results may have implications for survivorship care and counseling of these patients, and may justify secondary screening for SM as well as prolonged follow-up.

-Further research is necessary to confirm these findings, and to identify actionable mutations.

$\begin{array}{cccc}\text { Smoking history } & 18(11.5 \%) & 15(28.3 \%) & 0.004 \\ \text { Diabetes } & 9(5.8 \%) & 3(5.7 \%) & 0.76 \\ \text { Asian ethnicity } & 36(23.1 \%) & 10(18.9 \%) & 0.66 \\ \text { Stage 1a, 1b, 1c } & 92(59 \%) & 35(66 \%) & 0.46\end{array}$

Sunnybrook

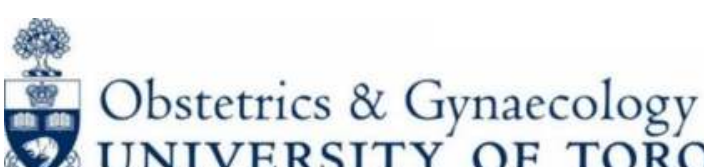

